\title{
Experimental Study on Seismic Behavior of High Strength Concrete Short Columns with High Axial Load Ratio
}

\author{
Guojun $\mathrm{ZHANG}^{1, \mathrm{a}^{*}}$, Benliang Liang ${ }^{1, \mathrm{~b}}$, Boquan $\mathrm{Liu}^{2, \mathrm{c}}$ \\ ${ }^{1}$ Architecture Engineering College, Shanghai Normal University, Shanghai 201418, China \\ ${ }^{2}$ Architecture Engineering College, Chang'an University, Xi'an 710061, China \\ azhgjxi@163.com, ${ }^{\mathrm{b}}$ lbl@shnu.edu.cn, ${ }^{\mathrm{c}}$ bqliu@chd.edu.cn
}

\begin{abstract}
Keywords: high strength concrete; hysteretic characteristic; ductility; axial load ratio; stirrup ratio; earthquake resistant behavior.

Abstracts: In order to research feasibility of high strength concrete applied to the framed structure of large-scale firepower plant, the 3 high-strength concrete short columns are experimentally researched. The results show that the stirrup ratio increases, the hysteretic curves of columns increasingly become full; the absorbed earthquake energy increases; the ductility and seismic performance also increased; the composite hoop columns always have good ductility as they fails.
\end{abstract}

\section{Introduction}

High strength concrete has been applied to a wide variety of the practical engineering, such as bridges, offshore platform and building engineering ${ }^{[1,2,3]}$, etc. The column section ${ }^{[4]}$ in the large thermal power plant is controlled by the limit values of axial compression ratio and their sectional dimension is usually larger, so it not only increase the structural weight but also frame column is not favorable for seismic brittle failure, poor ductility. At the same time, the weight increase to cause the seismic response increases, causing a vicious circle. High strength concrete is more brittle than ordinary concrete ${ }^{[5,6]}$. Experiments show that the confined high-strength concrete column with stirrups cannot reach the ductility of ordinary concrete columns under high axial compression ratio although it has been used in the very high rate of stirrup. On the other hand, because of the complexity of earthquake action, in the seismic analysis and design we have not yet raised ductility of columns is needed to achieve the extent to meet the requirements of many problems in seismic design also can only rely on the experience and judgment to solve and Many problems in seismic design also can only rely on the experience and judgment to solve. Based on mechanical properties tests of the 3 high strength concrete short columns under repeated loads, the influence of stirrup form and stirrup ratio on the failure modes, bearing capacity, hysteretic behavior and the ductility of high strength concrete short columns were researched.

\section{Experimental design and testing method}

Test specimen. The testing column was cantilever loaded column, whose shear span ratio is 1.5 ; the concrete strength grade is $\mathrm{C} 60$, by using the commercial concrete, and actually measured concrete strength index are shown in table 1; steel strength grade: grade I stirrup for hot rolled

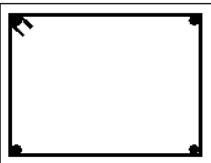

s-1

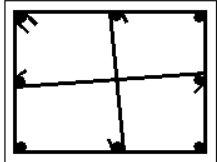

s-2

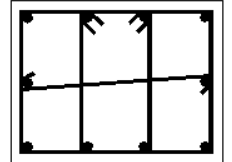

s-3

Fig. 1 hoop reinforcement form of test section column

Table 1 specimen size and reinforcement structure table steel, longitudinal reinforcement for grade II hot rolled reinforced bar; the designed axial compression ratio $\mathrm{n}$ is 0.8 ; the type of stirrups by this experiment is three types as shown in the figure 1; this time all the designed columns are strongly curved weak shear, and specimen size and reinforcement structure shown in table 1.

\begin{tabular}{|c|c|c|c|c|c|c|c|}
\hline specimen & bxh (mm) & $\begin{array}{c}\text { Column } \\
\text { height } \\
\mathrm{H}(\mathrm{mm})\end{array}$ & $\begin{array}{c}\text { hoop } \\
\text { reinforcement } \\
\text { form }\end{array}$ & $\begin{array}{c}\text { Stirrup } \\
\text { diameter } \\
\text { and } \\
\text { spacing }\end{array}$ & $\begin{array}{c}\text { Stirrup } \\
\text { volume } \\
\text { ratio } \rho \\
\mathrm{v} \%\end{array}$ & $\begin{array}{c}\text { Actual } \\
\text { longitudinal } \\
\text { reinforcemen } \\
\mathrm{A}_{\mathrm{s}}\end{array}$ & $\begin{array}{c}\text { Actual } \\
\text { reinforcement } \\
\text { ratio } \rho \text { s }\end{array}$ \\
\hline $\mathrm{HC} 1$ & $150 \mathrm{X} 300$ & 450 & $\mathrm{~S}-1$ & $\begin{array}{c}\varphi 6 \\
80\end{array}$ & 0.99 & $\begin{array}{c}402 \\
2 \Phi 16\end{array}$ & $2.02 \%$ \\
\hline $\mathrm{HC} 2$ & $150 \mathrm{X} 300$ & 450 & $\mathrm{~S}-2$ & $\begin{array}{c}\varphi 6 @ \\
80\end{array}$ & 1.49 & $\begin{array}{c}603 \\
3 \Phi 16\end{array}$ & $3.03 \%$ \\
\hline $\mathrm{HC} 3$ & $150 \times 300$ & 450 & $\mathrm{~S}-3$ & $\begin{array}{c}\varphi 6 @ \\
80\end{array}$ & 1.63 & $\begin{array}{c}603 \\
3 \Phi 16\end{array}$ & $3.03 \%$ \\
\hline
\end{tabular}


Methods of testing and loading program. The experiment was carried out on the pseudo static test of a counter force frame device at North Workshop in the structure laboratory of Xi'an University of Architecture and the loading system is cantilever column. A displacement meter installed in the column tops, which measure the horizontal displacement of column top under the horizontal action V1, and then the V - $\Delta 1$ curve of column top is obtained. First, a predetermined axial force vertical load was applied to the specimen, and remained constant, and then horizontal load was applied. The horizontal loads are adopted by load and displacement control method. Specimens are controlled according to the load value before yielding. After the specimen yield, specimens are controlled according to multiple recorded specimen yield displacement control cyclic loading $\triangle \mathrm{y}$. At the same time, as the degradation capacity, each displacement amplitude was $2 \sim 3$ times until the bearing capacity of the specimen is reduced to the maximum load of $80 \%$.

\section{The main test results and analysis}

The failure process and the failure form of description. The cracking loads of $\mathrm{HC} 1, \mathrm{HC} 2$ and $\mathrm{HC} 3$ columns are similar, namely the influence of stirrup ratio and hoop reinforcement form on the cracking load of specimen has little influence. The crack development and development situation of column $\mathrm{HC} 1$ is: in the first there appeared two horizontal cracks at the left edge of column positive, whose extension length was not very long, then the horizontal crack extended obliquely downward to the neutral axis; when the load kept loading, there appeared "X" crack near the neutral axis of the front and rear column and appeared horizontal cracks column on the left and right of columns, and there has also been a vertical cracks. When there appeared vertical cracks at the left and right edge of columns, it shows that the concrete in compression zone is crushed and the column attained its limit load. When the column reaches the limit load, start reciprocating loading, because the column stirrup ratio is smaller, when loading a week, it had huge slammed sound, the column sinking a few, the column occurred brittle shear failure suddenly. Due to brittle failure, so the cracks cracked wide $\mathrm{X}$. The crack width of this $\mathrm{X}$ down from the left behind is also very wide, that is to say in this direction is brittle fracture. The lower crack another direction of $\mathrm{X}$ is very wide, so there was the severe spalling of concrete on the back and on the right of the column. The crack development and development situation of column HC2 is: The number of the diagonal cracks appeared firstly near the neutral axis of the front column about $20 \mathrm{~cm}$ high, forming a " $\mathrm{X}$ " crack, and the rest throughout the crack distribution is also more, mainly to the inclined cracks, these cracks are essentially parallel to each other. In the column behind the crack distribution are steep, extending almost to the top of the specimen. There mainly appeared horizontal cracks through on the cross section in the side of the column. When the horizontal load was pushed and pulled at $350 \mathrm{kN}$, it reached the limiting load. At this time, there appeared vertical cracks at the lower left and lower right of the column front side; concrete began to fall, and it is not very clear " $\mathrm{X}$ " crack, and the crack development is not obvious, more dense, large crack angle, wide range of distributed. Start reciprocating loading, because the column stirrup ratio is moderate, when the cyclic loading, the crack development of $\mathrm{HC} 1$ column was slow; its load drop is not very fast; it took place the shear failure. The concrete spalling of the column root was not very serious. The crack developmentand development situation of column HC3 is: First, there appeared the horizontal cracks in the face and the back edge of the column, and then they extend downwards to form an extended long, wide " $\mathrm{X}$ " shaped inclined crack. The rest throughout the crack distribution is also more, mainly to the inclined cracks; these cracks are essentially parallel to each other. There mainly appeared horizontal cracks at the left and right side of column. There appeared vertical cracks at the lower left and lower right of the column front side, and concrete began to fall, and ' $\mathrm{X}$ ' - shaped crack was more and wider, which shows that the column had reached the limit load. When the loading head damaged, it began to turn to the one-way loading. Because the column stirrup ratio is more, when the one-way loading, crack development was slower than that of HC2 column, and load decreased slowly, it took placed the brittle shear failure. Due to brittle shear failure, therefore, the crack is not very wide of the $\mathrm{X}$ fracture, so the concrete off phenomenon was not serious. From the destruction of the phenomenon 
can see: due to the combined compression and shear effect of HC1 column, concrete main stress produced inclined crack, and crack is cross because of cyclic loading. As the crack was along the

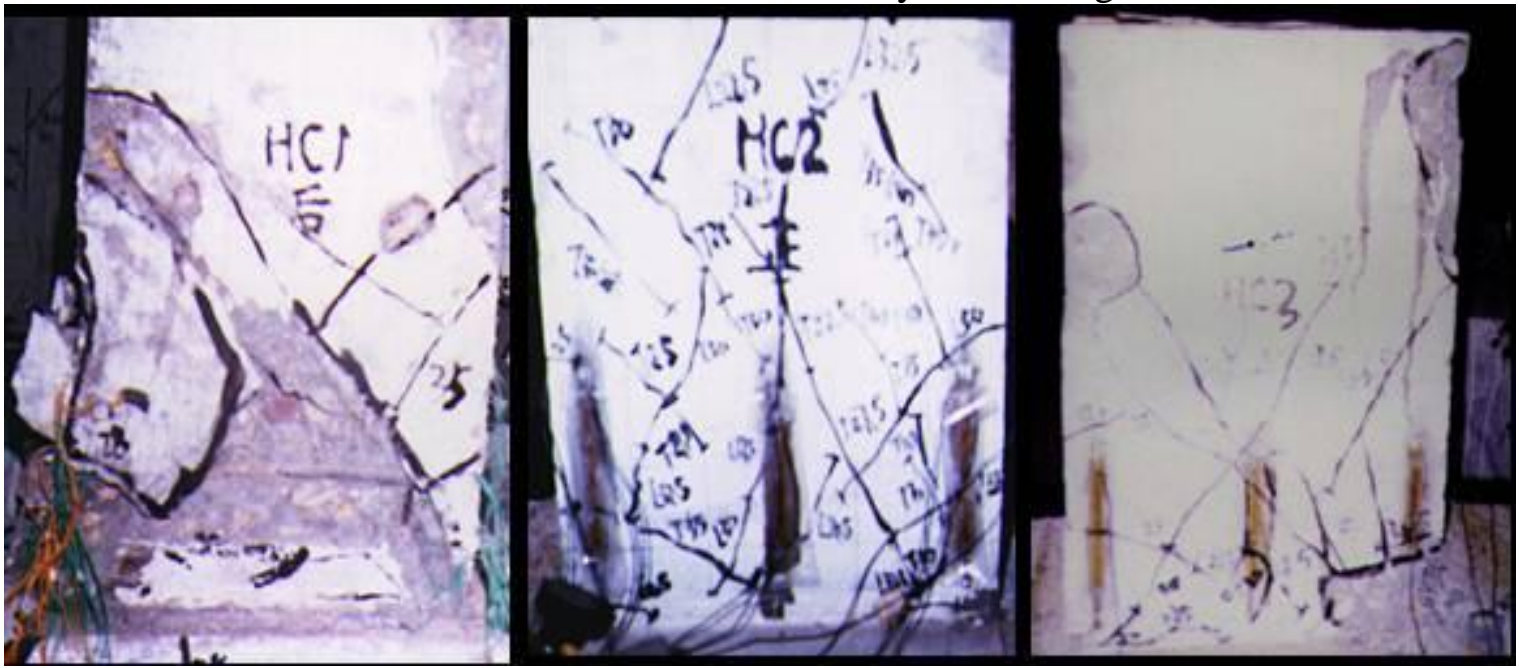

Fig.2 Damage picture of HC1 column Fig.3 Damage picture of HC2 column Fig.4 Damage picture of HC3 column diagonal line through the member reached the ultimate shear strength and took place instant damage. Stirrup stress increased rapidly in the appearance and development process of inclined cracks, most stirrup yielded and reinforcement not yielded, so the $\mathrm{HC} 1$ column failure belongs to destroy the diagonal shear ${ }^{[2]}$. The failure of specimen HC2 was same as with that of column HC1, but the crack width was not wide, its distribution and development of more dispersed, so better ductility. So the HC2 column failure belongs to the diagonal compression shear failure ${ }^{[2]}$. The failure of column $\mathrm{HC} 3$ was same as with that of $\mathrm{HC} 2$ column, so the HC3 column failure also belongs to the diagonal compression shear failure, but its ductility is much better than that of the HC2 column. This is mainly because the HC3 column with the composite hoop forms cross band brace.

Experimental results. The main test data shown in table 2.

Tab 2 Schedule of main test results

\begin{tabular}{|c|c|c|c|c|c|c|c|c|c|c|c|c|c|c|c|c|}
\hline \multirow{3}{*}{$\begin{array}{l}\text { Item } \\
\text { Specim } \\
\text { en }\end{array}$} & \multirow{3}{*}{$\begin{array}{l}\text { Cube } \\
\text { stren } \\
\text { gth } \\
\text { fuu }_{\text {cu }}\end{array}$} & \multirow{3}{*}{$\begin{array}{c}\text { The } \\
\text { actual } \\
\text { axial } \\
\text { compres } \\
\text { sion } \\
\text { ratio } \mathrm{n}_{\mathrm{c}}\end{array}$} & \multicolumn{6}{|c|}{ Cracking load and deformation } & \multicolumn{2}{|c|}{ Yield } & \multicolumn{2}{|c|}{ The maximum load } & \multicolumn{2}{|c|}{$\begin{array}{l}\text { The limit } \\
\text { deformation }\end{array}$} & \multirow{3}{*}{$\begin{array}{l}\text { Ductility } \\
\text { factor } \mathrm{s}^{2}\end{array}$} & \multirow{3}{*}{$\begin{array}{l}\text { Relative limit } \\
\text { angle } \theta(\%)\end{array}$} \\
\hline & & & \multicolumn{2}{|c|}{$\mathrm{V}_{\mathrm{BC}}(\mathrm{kN})$} & \multicolumn{2}{|c|}{$\mathrm{V}_{\mathrm{SC}}(\mathrm{kN})$} & \multicolumn{2}{|c|}{$\mathrm{V}_{\mathrm{VC}}(\mathrm{kN})$} & \multirow{2}{*}{$\begin{array}{c}\delta_{y} \\
(\mathrm{~mm})\end{array}$} & \multirow{2}{*}{$\begin{array}{c}\mathrm{V}_{\mathrm{y}} \\
(\mathrm{kN})\end{array}$} & \multirow{2}{*}{$\begin{array}{c}\mathrm{V}_{\mathrm{su}} \\
(\mathrm{kN})\end{array}$} & \multirow{2}{*}{$\begin{array}{c}\delta \mathrm{su} \\
(\mathrm{mm})\end{array}$} & \multirow{2}{*}{$\begin{array}{c}\delta \mathrm{u} \\
(\mathrm{mm})\end{array}$} & \multirow{2}{*}{$\begin{array}{c}\mathrm{V}_{\mathrm{u}} \\
(\mathrm{kN})\end{array}$} & & \\
\hline & & & left & right & left & right & left & right & & & & & & & & \\
\hline $\mathrm{HC} 1$ & 59.53 & 0.44 & 200 & 220 & 260 & 280 & 350 & 350 & 3.589 & 44.62 & & & 8. & 293 & .26 & 1.80 \\
\hline $\mathrm{HC} 2$ & .5 & 0.44 & 200 & 175 & 225 & 250 & 365 & 325 & 2.14 & 317.72 & -1 & 427 & 5.8 & 3 & 2. & 1.29 \\
\hline $\mathrm{HC} 3$ & 59.53 & 0.44 & 175 & 225 & 250 & 275 & 275 & 325 & 3.476 & 333.086 & 348.876 & 5.428 & 8.879 & 296.55 & 3.13 & 1.97 \\
\hline
\end{tabular}

Notes: $\mathrm{V}_{\mathrm{BC}}$ The horizontal force as bending cracks appeared; $\mathrm{V}_{\mathrm{SC}}$ The horizontal force as inclined cracks appeared; $\mathrm{V}_{\mathrm{VC}}$ The horizontal force as vertical cracks appeared.

The hysteretic curves and skeleton curves. This test carried out the experiment of 3 high-strength concrete short columns with high axial compression ratio under the cyclic loading, and their hysteretic characteristics are studied. The load displacement hysteretic curves and skeleton curves obtained from this test have the characteristics as follows:

(1) Under high axial compression ratio, the descending segment of skeleton curves of component hysteresis curves has a steep slope; the ductility of member is poorer. As the horizontal load reaches its maximum, the strength and stiffness decreases sharply;

(2) With the increase of the number of cycles, when the horizontal load exceeds the peak, cyclic loading will make the load carrying capacity and stiffness become obvious degradation phenomenon;

(3) Stirrup ratio has a significant effect on the hysteretic curve. For specimens with high stirrup ratio, their hysteretic curves are plump spindle stability; there are many cycle times; slow attenuation of strength, deformation capacity, the seismic performance of structure is improved significantly; Strength decay slow; there is a good deformation capacity; The seismic behavior of components is significantly improved;

(4) The hysteretic curves of this test members are not obvious pinch phenomenon, which prove 
that high strength concrete and longitudinal bars have better bond and the bond slip phenomenon does not occur between steel bar and concrete;

Ductility. Deformation performance of short column is related to many factor ${ }^{\mathrm{s}}[1,2,5,6]$, The more important of shear span ratio $\lambda$, axial compression ratio $n$, stirrup ratio ( $\rho$ sv, $\rho$ v) and hoop reinforcement form. The shear span ratio $\lambda$, axial compression ratio of the same $n$ the same, only the stirrup ratio $\left(\rho_{\mathrm{SV}}, \rho_{\mathrm{V}}\right)$ and type of stirrups of three short columns tested this time are different. The deformation properties of short columns were stud ied here mainly from these two aspects of the stirrup ratio and stirrup form. Under the same axial pressure ratio, the higher stirrup ratio is, the more obvious concrete confined effect is and the corresponding deformation properties of specimen are better. Hoop rate increases can be achieved from two aspects, one is increase the effective area of stirrups in the same stirrup spacing conditions, another is to reduce the stirrup spacing at the same hoop reinforcement form, and because of the influence of the higher rate for the former hoop is also that of the stirrups form. Therefore, in this experiment it is the influence on deformation performance of short columns that the corresponding increase of stirrup ratio compared only due to the increase of effective area namely the influence of stirrup form.

\section{Conclusions}

(1) The test columns took place shear compression failure. The " $\mathrm{X}$ " shaped diagonal crack width formed by broken column surface crack distribution has great relations with type of stirrups and stirrup ratio. The crack distribution of three columns HC1, HC2 and HC3 are more and more, also more and more narrow in turn. The three column width of crack are getting smaller and smaller, more and more light concrete off degree.

(2) With the stirrup ratio increases, the hysteretic curves of columns increasingly become full; the absorbed earthquake energy increases; the ductility and seismic performance also increased. The specimen does not increase the shear bearing capacity, but its ductility increase a lot as its stirrup ratio is very high.

(3) The ductility of high axial compression ratio rectangle hoop column is very poor, and it is not suitable for high strength concrete frame column. The composite hoop columns with high axial compression ratios always have good ductility as they fails, and they can meet the seismic performance requirements.

\section{References}

[1]Frédéric Lé geron and Patrick Paultre. Behavior of High-Strength Concrete Column under Cyclic Flexure and Constant Axial [J]. ACI Structural Journal, July-August 2000， 591-601 .

[2] Tong Yuesheng, Qian Guofang, Shi Qingxuan, Bai Guoliang. Shear strength analysis and the effect of stirrup ties of reinforced concrete short column[J]. Journal of building structures, 2000, 40(1), 109-111.

[3]Code for design of concrete structure (GBJ10-89) [M]. China Building Industry Press, 1989.

[4]Technical regulation for design of civil structure of thermal power plant (DL5022-93) [M]. China Power Press, 1993.

[5]China Civil Engineering Society, High strength and high performance concrete Committee. Technical specification for high strength concrete structures(CECS 104:99) [M]. Peking: China Engineering Construction Standardization Association, 1999.

[6]China Civil Engineering Society, High strength and high performance concrete Committee. The design and construction guide of reinforced concrete structure [M]. Peking: China Building Ind ustry Press, 2001. 